\title{
Analysis of Hull Coating Renewal in Ship Repairing
}

\author{
Arun $\mathrm{Kr} \mathrm{Dev}^{\star}$ and Makaraksha Saha ${ }^{\dagger}$ \\ ${ }^{*}$ Newcastle University International Singapore, Singapore \\ ${ }^{\dagger} M K$ Marine Pte Ltd, Singapore
}

\begin{abstract}
Hull coating (external blasting and painting) renewal (repair) is a part of routine ship maintenance. It is carried out only when the ship is in a dock (graving dock, floating dock, or slipway). For a regular maintenance schedule, the scope of hull coating repairing works dictates the duration of stay of a ship in the dock. It is very vital therefore to estimate the scope of work for hull coating before docking. As soon as the ship is docked, a joint hull inspection by representatives of the owner, drydock, and coatings supplier accurately determines the hull coatings scope of work. Most of the time, the inspection result does not match with the preplanned dock operation schedule. Hence, the overall dock operation schedule gets affected due to delay or early undocking of a ship. Hull coating repair and related information for 149 cargo ships were collected from a single shipyard. It was analyzed and presented in both tabular and graphical forms to show the relationship between the scope of work and the age, size, and type of ships. The physical size of a ship has a great influence on the hull blasting and painting repairing works irrespective of design parameters and types of the ship. Using ship dimensions, actual surface area, and other factors, a method of estimating the hull coating scope is proposed. In this article, the authors have made an attempt to identify the independent variables that influence the scope of work (dependent variable), and suggested the possible interrelationships between the dependent and independent variables, which appeared to be linear.
\end{abstract}

Keywords: hull coating; hull total area; blasting area; painting area; age; deadweight; type; locations; dimensions

\section{Introduction}

For A newly built ship, the external hull is coated with two types of painting system, namely, anticorrosive painting system and antifouling painting system. Anticorrosive painting system is to protect the steel from corrosion caused by oxidation, and antifouling painting system is to protect the underwater surface from marine growth. After proper surface preparation, multiple coats of anticorrosive paint are applied to the entire hull (underwater and above water) as per painting schemes followed by multiple coats of antifouling paints to the underwater area.

Boottop area is always subjected to be in and out of water alternately. The top coat in this area is of different quality to meet

Manuscript received by JSPD Committee May 7, 2016; accepted July 25, 2016. the requirements. It is worth to mention that for some ships, boottop area is not demarked separately but included in the vertical bottom area under the antifouling paint. As such, the repairing of hull coating refers to the renewal of anticorrosive and antifouling painting system.

Corrosion is considered to be the most influencing factor that affects the physical life of steel structures, on shore or at sea, and its initiation is also deemed to be an unavoidable natural phenomenon. A ship, being made of steel, is not an exception from the influence of this natural phenomenon. The physical life of a ship structure is substantially affected by the corrosion phenomenon after its commissioning, and the problems of corrosion and wear are the most important factors in securing the safety and reliability of hull structural steel; (Paik et al. 1998; Yamamoto \& Ikegami 1998).

The conventional way of treating this corrosion problem, being unavoidable due to a natural phenomenon, is 1) to use a 
corrosion margin for the structural members at the design stage or 2) to use protective coatings against the corrosion phenomenon to enhance the effective life by reducing the corrosion rate (Yamamoto \& Ikegami 1998). Sacrificial anode system (zinc and aluminum anode) and impressed current cathodic protection system are also used. These two systems protect the steel against galvanic corrosion caused by the presence of nonferrous materials such as bronze and brass used for the propeller, rudder pintle bush, sea valve disc, seat, and so forth.

In addition to various corrosion effects on floating structures like ships, fouling is a serious problem to tackle throughout the ship's service life. Fouling is a natural phenomenon that involves the growth of the marine animal and vegetable on the ship's underwater surface. This growth increases the resistance of a ship against water and reduces the speed. Marine growth is unavoidable but can be reduced to a great extent by applying antifouling paint to the underwater area.

This article focuses on the surface preparation and protective coating only, particularly, on the hull (external) coating of a ship and its repair irrespective of blasting standard, types of paint, and number of coats. Emphasis is particularly given to the total area blasted and painted.

Basic hull coating repairing process/system can be explained as follows: upon confirmation of scope of hull coating repairing works by representatives of owner and paint manufacturer, the activity starts with blasting, such as spot blasting (to remove the paints from rusty spot, paint damaged area, etc.) or full blasting (to remove the paint from entire area) to get a bare metal surface. Then the application of paint starts as per painting schemes such as single or multiple coats (touch-up of anticorrosive paint to the spot blasted area) and single or multiple coats (full area, i.e., the entire hull surface with anticorrosive and antifouling paint).

Hull coating repair is a part of the routine maintenance work of a ship during its operating life. Because of the nature of the repairing works, this can only be carried out in a dock (graving dock, floating dock, and slipway). Rules and regulations of classification society and flag state require a ship to call to a shipyard for various inspections. As per rules and regulations of a classification society and the flag state, with an average interval of 12-30 months, a ship is required to carry out annual survey, docking survey, intermediate or special survey (every 5 years), and other inspections according to the survey status based on the age of the individual ship. For a routine dock maintenance schedule, external hull coating repair (blasting and painting) is the important activity and key factor to decide the duration of stay of a ship in the dry dock. The scope of hull coating repairing works normally dictates the dry-docking time. Because of the cost fac- tor, more dry-docking time means more cost, and as such both the owner and shipyard would like to minimize the dry-docking time. It can easily be translated into a lower cost for the owner and a larger number of ships in the dock in a particular time (a year) for the shipyard that will increase turnover and profit. It is, therefore, very critical for the owner and shipyard to minimize the dry-docking time. To achieve this, spot-on information about the hull coating repairing scope is essential. It will help the owner to budget costs and the shipyard to plan docking schedules perfectly.

The hull coating repairing scope is determined on the spot after bottom inspection by the representatives of the owner, shipyard, and paint supplier. Most of the time, the extent of the bottom survey exceeds the scope outlined in the repair specification. An increase in the dry-docking time causes problems for the shipyard to meet the dry-docking schedule for subsequent ships. This problematic situation can be improved or avoided if reliable and accurate information about the hull coating repairing scope for the ship in question is available in advance of the dry-docking survey.

In this article, coating repairing activities are divided into 1) hull blasting and 2) hull painting, and these are measured in terms of blasting area $\left(\mathrm{m}^{2}\right)$ and painting area $\left(\mathrm{m}^{2}\right)$ against various hull locations such as topside (TS), boottop (BT), vertical bottom (VB), and flat bottom (FB). This analysis covers only ships with regular docking repair, and not emergency, damage, or afloat repair. It should then provide a more uniform, reliable, and realistic relationship among the variables for the analysis (See Typical midship section).

The aims of this article were to investigate and establish the interrelationship among the dependent and the independent variables for hull coating repairing works. Data collection and analysis are carried out both analytically and graphically for dealing with the tasks.

A review of the related literature is highlighted in section 2. In section 3, the problem formulation and related assumptions are discussed. Data collected and initial findings are presented in section 4. Analysis of hull blasting and hull painting are presented in graphical form in section 5. An approach for estimation of blasting and painting repairing work scope before docking is explained in section 6. In section 7, results of analysis and application of findings are discussed. Finally, section 8 concludes the article and proposes suggestions for future research works.

\section{Literature review}

There is no documented information available about hull coating repairing of ships regarding their age, deadweight, and type.

\section{Nomenclature}

\begin{tabular}{|c|c|c|}
\hline$A_{H T}=$ hull total area $\left(\mathrm{m}^{2}\right)$ & $A_{B T B}=$ boottop blasting area $\left(\mathrm{m}^{2}\right)$ & $A_{F B P}=$ flat bottom painting area $\left(\mathrm{m}^{2}\right)$ \\
\hline$A_{T S}=$ topside total area $\left(\mathrm{m}^{2}\right)$ & $A_{V B B}=$ vertical bottom blasting area $\left(\mathrm{m}^{2}\right)$ & $A_{V S P}=$ vertical side $(\mathrm{BT}+\mathrm{VB})$ painting $\left(\mathrm{m}^{2}\right)$ \\
\hline$A_{B T}=$ boottop total area $\left(\mathrm{m}^{2}\right)$ & $A_{F B B}=$ flat bottom blasting area $\left(\mathrm{m}^{2}\right)$ & $B_{m l d}=$ breadth molded $(\mathrm{m})$ \\
\hline$A_{V B}=$ vertical bottom total area, $\mathrm{m}^{2}$ & $A_{V S B}=$ vertical side $(\mathrm{BT}+\mathrm{VB})$ & $D_{m l d}=$ depth molded $(\mathrm{m})$ \\
\hline$A_{F B}=$ flat bottom total area $\left(\mathrm{m}^{2}\right)$ & blasting area $\left(\mathrm{m}^{2}\right)$ & $L_{O A}=$ length overall $(\mathrm{m})$ \\
\hline $\begin{array}{c}\left.A_{V S}=\underset{\text { vertical side }(\mathrm{BT}}{\text { total area }\left(\mathrm{m}^{2}\right)}+\mathrm{VB}\right) \\
\text { tal }\end{array}$ & $\begin{aligned} A_{H P} & =\text { hull painting area }\left(\mathrm{m}^{2}\right) \\
A_{T S P} & =\text { topside painting area }\left(\mathrm{m}^{2}\right)\end{aligned}$ & $\begin{array}{l}S_{A}=\text { ships' age (year) } \\
S_{D}=\text { ships' deadweight (metric ton) }\end{array}$ \\
\hline$A_{H B}=$ hull blasting area $\left(\mathrm{m}^{2}\right)$ & $A_{B T P}=$ boottop painting area $\left(\mathrm{m}^{2}\right)$ & $T_{\max }=$ summer draft at maximum load line (m) \\
\hline$A_{T S B}=$ topside blasting area $\left(\mathrm{m}^{2}\right)$ & $A_{V B P}=$ vertical bottom painting area $\left(\mathrm{m}^{2}\right)$ & $T_{\min }=$ summer draft at light load line $(\mathrm{m})$ \\
\hline
\end{tabular}




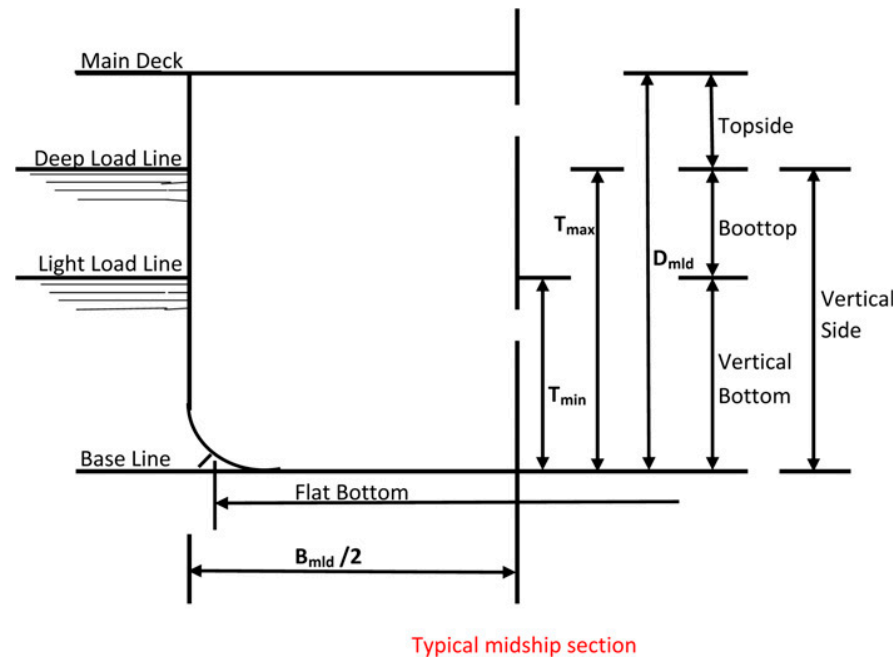

Such information could be useful for the ship owners and ship managers to estimate the scope of hull coating repairing works. However, some works, not exactly but close to the issue, were done from different viewpoints.

Broderick et al. (2012) explored the link between structural complexity in water ballast tanks (WBTs) and coating performance in the context of the introduction of the International Maritime Organization Performance Standard for Protective Coatings for dedicated WBTs, with an objective to propose how future ship structural design may be improved to enhance the coating performance. This article highlighted the classification of complexity of coating surface described by Jotun (2001) where the flat surfaces of the ship's hull are classed as low, the cargo holds of a bulk carrier are given a medium rating, and WBTs are classed as very high. It also suggested that there was only a relatively small feasible region in the design space within which alternative stiffener types and scantlings could be proposed to seek such benefit on the coating performance.

Garbatov et al. (2006) investigated the corrosion development and wastage of deck plates of WBTs and cargo oil tanks (COTs) for tankers. They developed a nonlinear time-dependent corrosion wastage model for the deck plate. The model can describe an initial period without corrosion due to the presence of a corrosion protection system (tank coating), a transition period with a nonlinear increase in wastage up to a steady state of long-run corrosion wastage that leads to plate replacement. The model also predicts that the periods without corrosion for the WBT and the COT deck plate, which corresponds to the start of failure of corrosion protection coating, are 10.54 and 11.49 years, respectively, and the transition periods for the same are 11.14 and 11.23 years, respectively.

Hiromi et al. (2006) investigated the reduction in wall thickness of various shipboard piping systems resulting from flow-accelerated corrosion, under different flow conditions and pipe geometry. They also proposed the use of Kastner's experimental formula to estimate the reduction in wall thickness of pipelines onboard.

Nakai et al. (2007) studied the corroded condition of webs of cargo hold frames of a bulk carrier and investigated the effect of corrosion pitting and its contribution to ultimate strength, particularly, the webs of hold frames of a bulk carrier that carries iron ore and coal. They developed a method of visual assessment of corroded conditions and various parameters required to calculate the ultimate strength. They also prepared and proposed a method to estimate the equivalent thickness loss of web plate using the depth of pitting and the residual strength of members with pitting corrosion. Their predicted result of tensile strength strongly corresponds with the experimental result.

O'Donnell (2006) provided an overview on the corrosion fatigue of the most commonly used carbon and low-alloy steels and stainless steel, and its developments and future needs taking into consideration of environmentally assisted cracking. He presented compilation and analysis of available database and suggested environmental fatigue curve for carbon and alloy steels and austenitic stainless steels.

Paik et al. (1998) investigated the effect of corrosion on the ultimate strength of a structural member of ships' structure. They developed and demonstrated a procedure for assessment of ship hull girder ultimate strength reliability taking into account the degradation of primary members due to general corrosion. A probabilistic model for ultimate hull girder strength is established by an analytical formula that considers corrosion-related time-dependent strength degradation in various failure modes. The variability in strength, corrosion rates, and loads accounted for the second-order reliability method used for the calculation of the time-dependent reliability index. The procedure developed is illustrated by application to both tankers and bulk carriers. For a given set of renewal criteria, apart from trends of hull girder section modulus, ultimate strength, and the reliability index as a function of vessel age, the probability of steel renewal due to corrosion is also predicted.

Yamamoto and Ikegami (1998) investigated the corrosion phenomenon of ship's hull consisting three sequential processes such as 1) degradation of paint coatings, 2) generation of pitting points, and 3) progress of pitting point. They described each process by introducing probabilistic corrosion model. This probabilistic corrosion model can be developed by analyzing existing data collected from plate thickness measurements. By comparing the results of estimations by the identified probabilistic models and actual measurement data, the practical usefulness of the proposed procedure is proved.

Moreover, there are no guidelines available that could be useful for the ship owners and ship managers for a reliable estimation of the scope of hull coating repairing works. The probable reason seems to be the scarcity and confidentiality of such commercially sensitive information and data. Normally, details of coating repair such as blasting quality and quantity, types of paint, and the number of coats are not disclosed to other than the concerned parties. As such, there is little opportunity for information sharing of this valuable ship maintenance item.

Hull coating repairing activity, other than new building, is divided into two broad segments, surface preparation and paint application. Surface preparation includes high-pressure fan jet washing of hull to remove salt contaminant and loose rust, followed by scrapping to remove barnacles and other marine growths. Then a joint inspection, including representatives of the owner, shipyard, and the paint manufacturer, is carried out and agreed upon the scope of hull coating repairing scope. Upon confirmation of scope of work, all logistics are arranged and equipment are made available, such as cherry pickers, air compressors, blasting equipment, and painting equipment (preparation time). This preparation time could be optimized if a simple guideline about the scope of coating repairing regarding age, deadweight, and type of ship were available. This 
lack of information motivated the authors, who have more than three decades of direct experience in marine and offshore industries, particularly in repairing and new building of various types and sizes of ships, to take the task of this research of hull coating repair (renewal).

\section{Problem formulation and related assumptions (key variables)}

\subsection{Problem formulation}

Because of the nature of the underwater hull coating repair, this work can only be done in a dock. As such, in every drydocking, there are always some amount of coatings repair to be carried out. It is evident from the sequential process of hull coating repairing that the estimation of repairing scope is hardly possible, almost impossible, without bringing the ship in a dock. Concerned parties need to wait for the vessel to go to the dock before confirmation of scope of repairing works. This situation leaves the owner and shipyard in an uncertain situation on the commercial commitment for the owner and schedule of dock operation for the shipyard. Although the owner provides a scope of hull coating repairing to the shipyard before a ship's arrival, the shipyard then uses it as a guide for the dock operation. However, in most cases, the actual scope is different and much more. It puts the shipyard management in a difficult situation to accommodate additional days in the dock. This uncertainty may be overcome if a simple guideline to estimate the expected scope of hull coating repairing of a ship's age, deadweight, type, and principal dimensions is available beforehand.

\subsection{Related assumptions (key variables)}

3.2.1. Ships' age. The age of a ship at the time of the hull coating repair is the time (years) for which the ship has been in service. It is counted from the date of delivery of a ship from its builder to the owner. It can be considered as the date of birth of a ship, and it is used in all documents/certificates issued for the first time by the underwriter, the flag administration, and the classification society. As a ship becomes older, the quality of steel surface deteriorates, from various viewpoints, such as chemical properties (metallurgical), mechanical properties (structural strength), and physical properties (surface roughness, bonding to coating, etc.) due to the natural causes. It is expected that older ships will have more blasting and painting works than new ships. Moreover, multiple coats of antifouling paint are applied to the ship's underwater hull considering the estimated time of subsequent docking (generally 30-36 months). It is considered as the paint life or coating life. During this period, properties of antifouling paint are reduced, and after the designated lifetime, it is entirely gone. Under this condition, whether corrosion appeared or not, blasting is carried out or not, new antifouling paint must be applied, after appropriate surface preparation, to the underwater hull to protect the hull up to next docking. Therefore, the age of a ship has a positive impact on hull coating repairing scope, and they are expected to be linearly associated. It means that with the increase of age of a ship, the quantity of hull coating repairing scope will be linearly increased. In other words, older ships will have more hull coating repairing works compared to newer ships.
3.2.2. Ships' deadweight. Deadweight of a ship is the weight it can carry including its cargo and consumables. Higher deadweight means bigger size, resulting in larger external surface areas. Thus, logically the bigger ships will have greater coating repairing areas. Hence, the deadweight/gross tonnage will have a link to repair demands. It means that with the increase of deadweight/gross tonnage of a ship, the quantity of hull coatings repairing scope will be linearly increased. In other words, bigger ships will have more hull coating repairing works compared to smaller ships.

3.2.3. Ships' type. The types of ships mainly relate to the type or nature of cargoes carried. Because of the type of the shipment and nature of the cargo, the configuration of a ship varies widely including operational and performance requirements. For example, a crude oil tanker loads cargo from an oil field/oil terminal and unload straight at a refinery, no loading or unloading in between. On the other hand, a container carrier or a product tanker loads cargo from the home port and call on all ports in the designated voyage route and carry out loading and unloading operation until it reaches the home port for complete discharge of cargo, just like a city bus service. The service speed of a container carrier is much higher than that of a crude oil tanker, a bulk carrier, a product tanker, and so on, which has a significant impact on the ship's underwater surface and hence, the demand for coating repair. It means that the different types of ships, with the same age and deadweight, will have the different quantity of hull coating repairing scope.

3.2.4. Ships' dimensions. There is no argument that the physical size of a ship significantly influences the scope of hull blasting and painting repairing works. The physical size of a ship refers to length overall, breadth, and depth. Physically bigger ship means greater hull surface area, which is the main element to decide the quantity of hull blasting and painting repairing works. In other words, physically bigger ships will require more blasting and painting repairing works compared to smaller ships, and they are linearly associated. Therefore, the physical dimensions of a ship have an impact on the hull coating repairing scope, and they are linearly associated.

\section{Sample data and methodology}

\subsection{Data collection}

A total of 149 cargo ships were selected to study and analyze the coating repair (blasting and painting quantity) of the external hull surface area and verify the assumptions. These ships were repaired in a shipyard during the period June 2006 to April 2012. Their scope of coating repairing works, age, deadweight, and types was collected. Since all these ships were handled in the same shipyard, the collected data were free from any geographical influences. Geographical influences refer to the regional effect on efficiency and skill of the workforce, facilities, and equipment for hull coating repairing works and overall shipyard's facilities and capabilities, which directly influence the quality and productivity of the blasting and painting works. Since the present study uses the quantity of hull coating repairing works, the result of this research may have broader application. 
Table 1 Specification of sampled ships averaged over the number of ships

\begin{tabular}{|c|c|c|c|c|c|c|c|c|}
\hline Type & No. of ships & \multicolumn{7}{|c|}{ Average } \\
\hline Crude oil tanker & 104 & 8.6 & 168,117 & 24,024 & 2,846 & 42,743 & 11.84 & 177.92 \\
\hline LPG carrier & 11 & 13.3 & 41,405 & 13,353 & 2,155 & 26,300 & 16.14 & 196.95 \\
\hline Chemical tanker & 11 & 7.1 & 46,283 & 11,029 & 1,784 & 23,840 & 16.17 & 216.16 \\
\hline Bulk carrier & 7 & 10.3 & 111,355 & 18,146 & 3,978 & 35,908 & 21.92 & 197.88 \\
\hline
\end{tabular}

A general picture of sample data for hull coating repairing works is presented in a tabular form in Table 1 and graphical form in Figs. 1-8. Table 1 shows the average values of ships' age, deadweight, hull total area, hull blasting area, hull painting area, and hull blasting area as a percentage of hull total area and the painting area as a percentage of hull total area against the var-

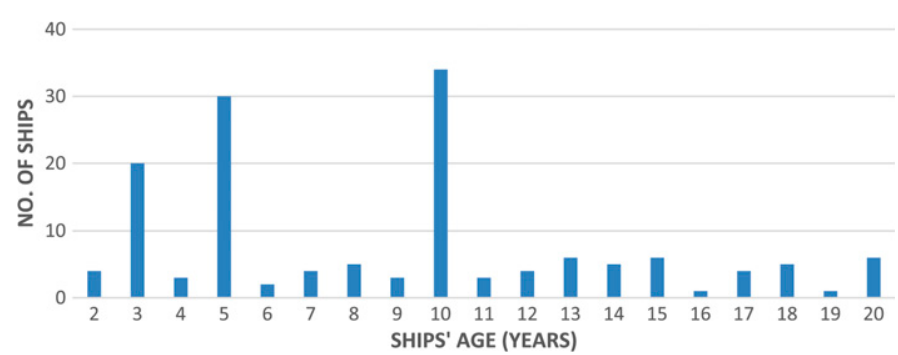

Fig. 1 Distribution of age of sample ships

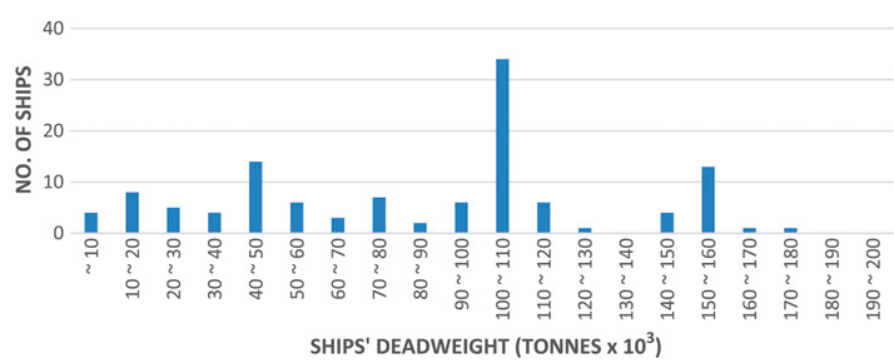

Fig. 2 Distribution of deadweight of sample ships

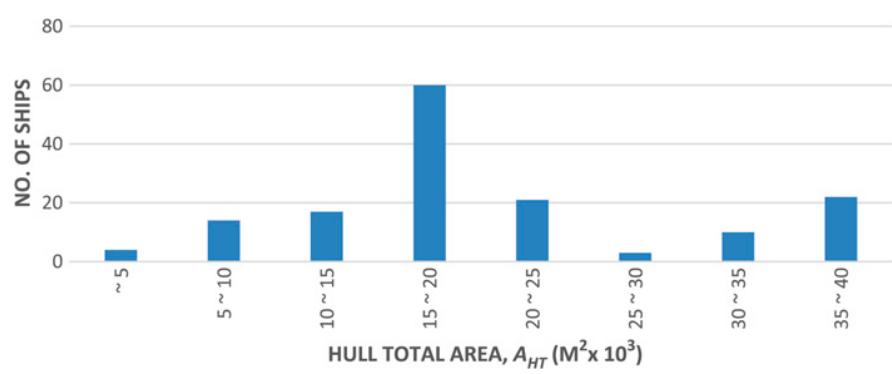

Fig. 3 Distribution of hull total area of sample ships ious types of ships. Figures 1-5 show the distribution of various independent variables. It also shows the limiting value of the variables. It can be seen in Fig. 1 that most of the sample ships (about $98 \%$ ) are within 20 years of age limit. Figure 4 shows that most of the sample ships (about $91 \%$ ) are within $6500 \mathrm{~m}^{2}$ of blasting area limit. Similarly, other figures also depict the limiting

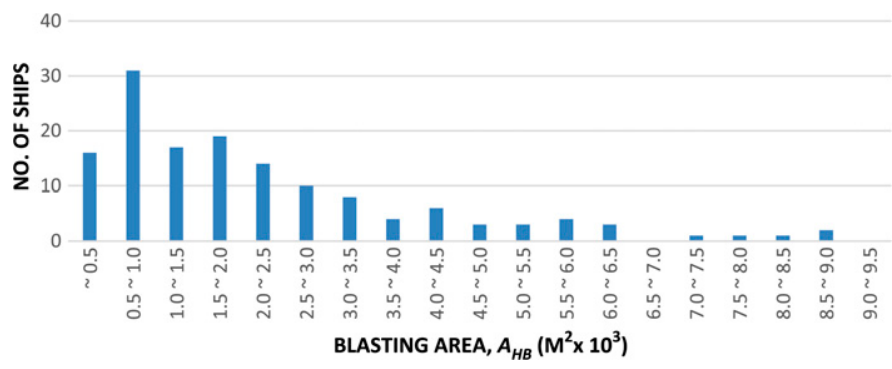

Fig. 4 Distribution of hull blasting area of sample ships

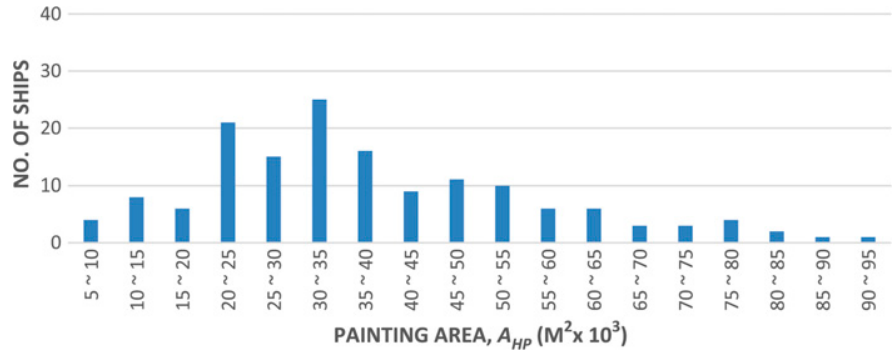

Fig. 5 Distribution of hull painting area of sample ships

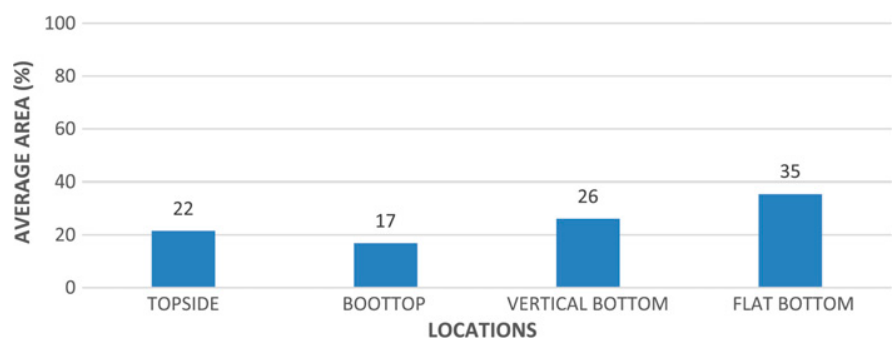

Fig. 6 Average hull location area (\% of $\left.A_{H T}\right)$ versus hull locations of sample ships 


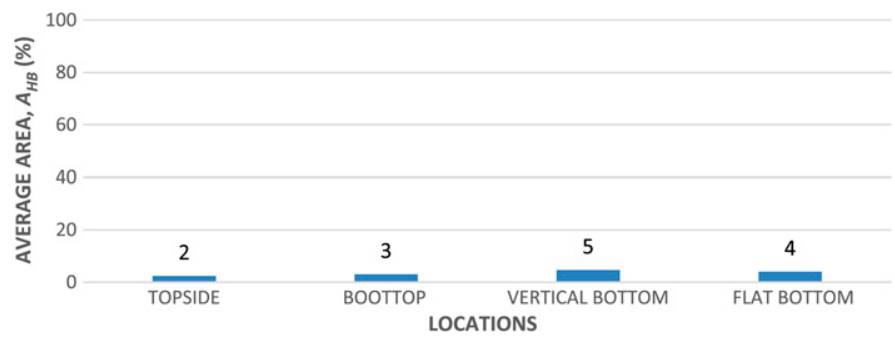

Fig. 7 Average hull blasting area (\% of $A_{H T}$ ) versus hull locations of sample ships

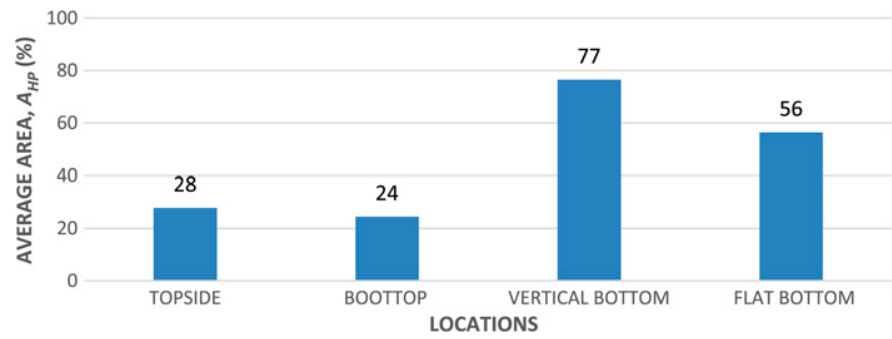

Fig. 8 Average hull painting area (\% of $A_{H T}$ ) versus hull locations of sample ships

values of other variables accordingly. Figures 6-8 show the percentage breakdown of average hull total area, average hull blasting area, and average hull painting area among the locations (topside, boottop, vertical bottom, and flat bottom), respectively.

Average area refers to the arithmetic mean of areas of the same locations, such as topside, boottop, vertical bottom, flat bottom, and hull total, of sample ships. Figure 6 shows the breakdown of hull total area $\left(A_{H T}\right)$ regarding areas of locations, such as topside $\left(A_{T S}\right)$, boottop $\left(A_{B T}\right)$, vertical bottom $\left(A_{V B}\right)$, and flat bottom $\left(A_{\mathrm{FB}}\right)$ in the percentage of hull total area $\left(A_{H T}\right)$. In other words, it shows the contribution of locations into the hull total area. Similarly, Fig. 7 shows the breakdown of hull blasting area $\left(A_{H B}\right)$ regarding blasting area of locations, such as topside $\left(A_{T S B}\right)$, boottop $\left(A_{B T B}\right)$, vertical bottom $\left(A_{V B B}\right)$, and flat bottom $\left(A_{F B B}\right)$ in the percentage of hull total area $\left(A_{H T}\right)$. In other words, it shows the contribution of locations into the total blasting area. Figure 8 shows the breakdown of hull painting area $\left(A_{H P}\right)$ and cumulative area including touch-up and full with respective to the number of coats, regarding painting area of locations, such as topside $\left(A_{T S P}\right)$, boottop $\left(A_{B T P}\right)$, vertical bottom $\left(A_{V B P}\right)$, and flat bottom $\left(A_{F B P}\right)$ in percentage of hull total area $\left(A_{H T}\right)$. In other words, it shows the contribution of locations to the total painting area.

\section{Hull coating}

\subsection{Hull blasting}

Initial investigations of pairs of variables of interests related to hull blasting area are shown in Figs. 9-16 and corresponding $r^{2}$ values assuming a linear relationship and a nonlinear relationship (exponential) are presented in Table 2. Figures 9 and 10 show the relationship between hull blasting area (observed values), average hull blasting area by age group against ships' age (total blasting repairing area for a particular age group divided by the

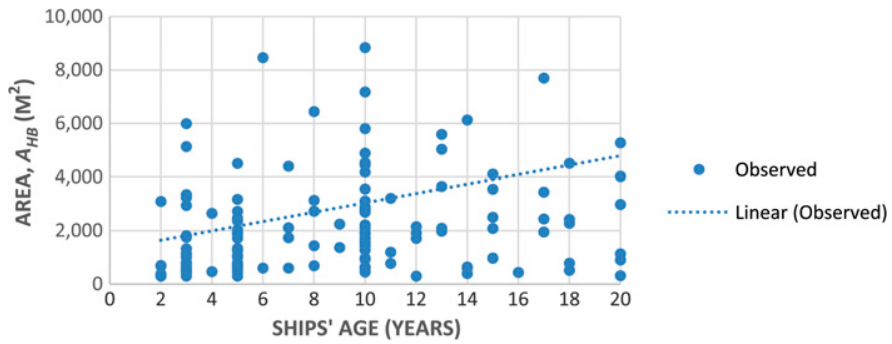

Fig. 9 Hull blasting area versus age of sample ships

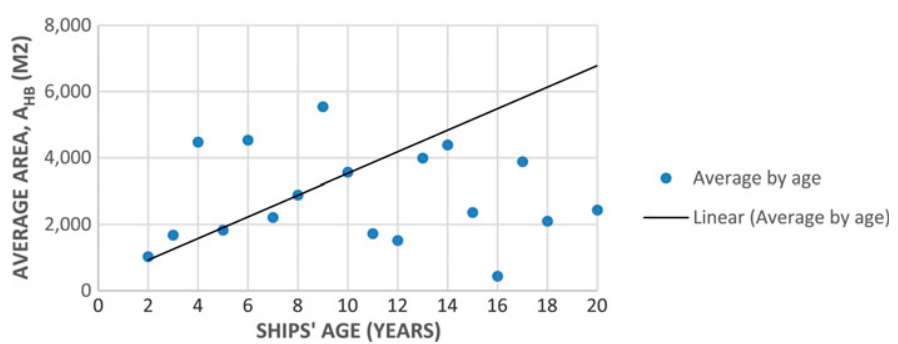

Fig. 10 Average hull blasting area versus age of sample ships

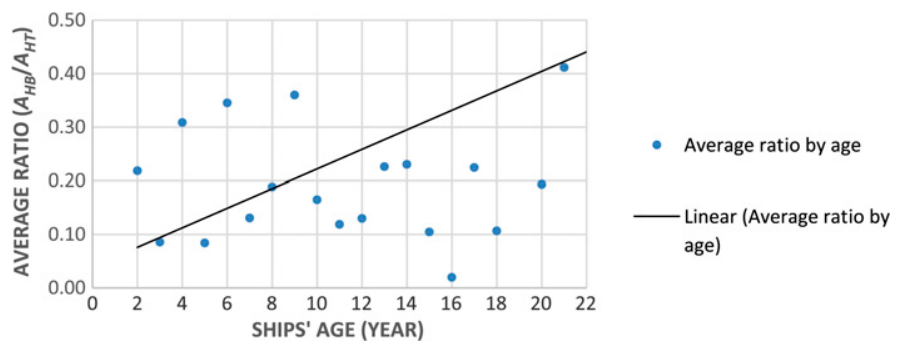

Fig. 11 Average ratio $\left(A_{H B} / A_{H T}\right)$ versus age of sample ships

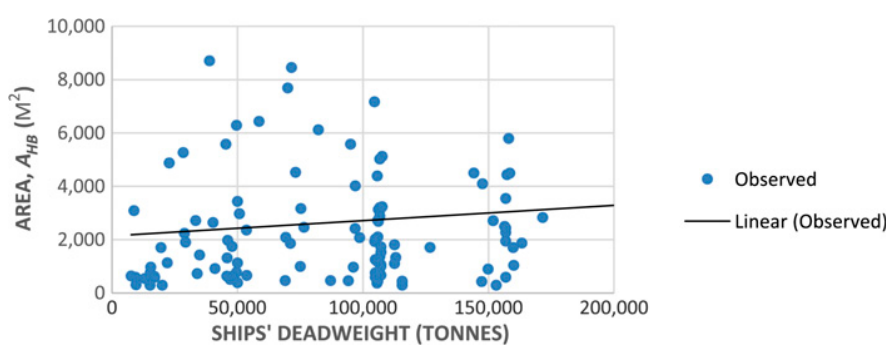

Fig. 12 Hull blasting area versus deadweight of sample ships

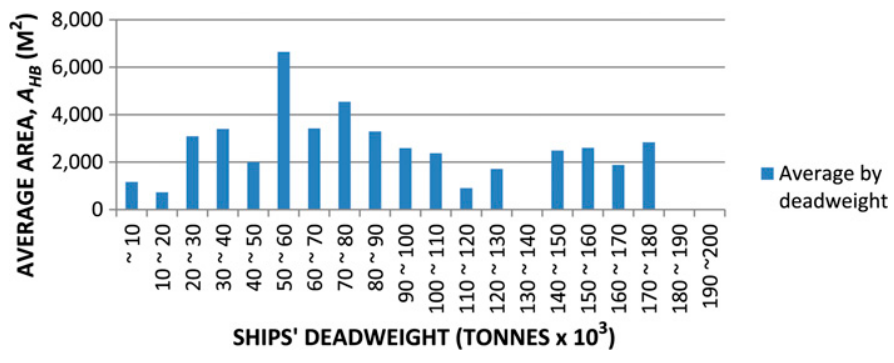

Fig. 13 Average hull blasting area versus deadweight of sample ships 


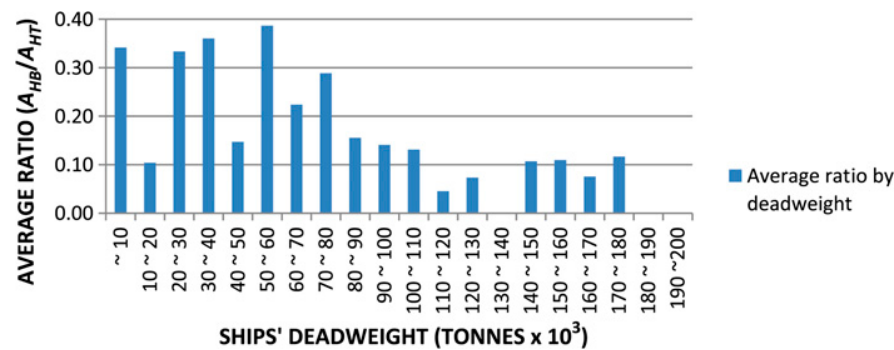

Fig. 14 Average ratio $\left(A_{H B} / A_{H T}\right)$ versus deadweight of sample ships

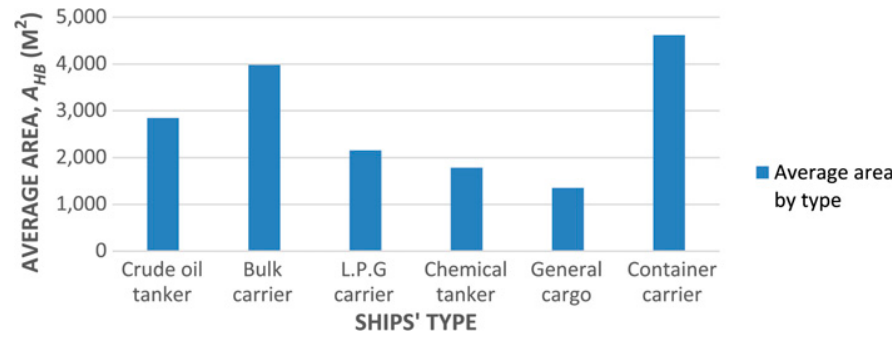

Fig. 15 Average hull blasting area versus types by typical design speed order

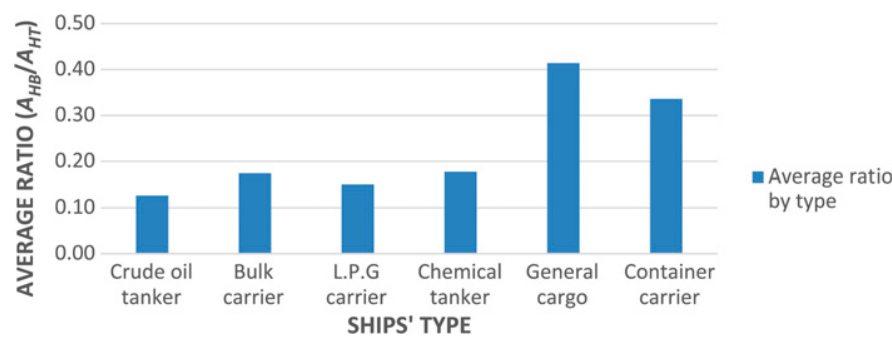

Fig. 16 Average ratio $\left(A_{H B} / A_{H T}\right)$ versus types by typical design speed order

total number of ships under the same age group), respectively. In Fig. 9, points are widely scattered, but in Fig. 10, points are less scattered, and this is supported by the higher $r^{2}$ value $(0.074$ and 0.2841 , respectively) in Table 2 . In both cases, blasting area $\left(A_{H B}\right)$ shows a trend of linear relationship with ships' age.

Table 2 Summary of correlation coefficients under linear and exponential relationship

\begin{tabular}{ccc}
\hline & \multicolumn{2}{c}{$r^{2}$ value } \\
\cline { 2 - 3 } Figure no. & Linear relationship & Exponential relationship \\
\hline 9 & 0.0740 & 0.0919 \\
10 & 0.2841 & 0.1981 \\
11 & 0.2724 & 0.1128 \\
12 & 0.0261 & 0.0277 \\
13 & $0.0059(-)$ & $0.0050(-)$ \\
14 & $0.3358(-)$ & $0.2985(-)$ \\
15 & 0.0006 & 0.0130 \\
16 & 0.6767 & 0.7516 \\
\hline
\end{tabular}

Figure 11 shows the relationship of the average ratio of hull blasting area to hull total area $\left(A_{H B} / A_{H T}\right)$ against ships' age. It shows a trend of linear relationship with ships' age with $r^{2}$ value of 0.2724 (Table 2). Mathematically, it means that hull blasting area, if not sufficiently significant, has a positive and linear relationship with ships' age, which is in line with the assumption.

Figures 12 and 13 show the relationship between hull blasting area (observed values), average hull blasting area by the deadweight group against ships' deadweight (total blasting repairing area for a particular deadweight group divided by the total number of ships under the same deadweight group), respectively. Both figures show very loose linear relationship between hull blasting area and ships' deadweight, and it is supported by the insignificant $r^{2}$ values ( 0.0261 and 0.0059 with negative slope, respectively) in Table 2. Mathematically, it means that bigger ships (larger deadweight) may or may not have more blasting repairing activity, although there is a trend of a linear relationship.

Figure 14 shows the relationship of the average ratio of hull blasting area to hull total area against ships' deadweight. It shows a trend of linear relationship with a negative slope and $r^{2}$ value of 0.3358 (Table 2). Mathematically, it means that the rate of change of deadweight is much higher than the rate of change in corresponding blasting repairing area. It leads to a lower ratio for higher deadweight.

Figure 15 shows the relationship between the average hull blasting area by ship type against the types of ship with a linear relationship and $r^{2}$ value of 0.0006 (order of ship type is by typical design speed of ship type). It shows that container carriers have the highest and general cargo carriers have the lowest blasting repairing activities.

Figure 16 shows the relationship between the average ratio of hull blasting area to hull total area $\left(A_{H B} / A_{H T}\right)$ by ship type against the types of ships with a trend of a linear relationship and $r^{2}$ value of 0.6767 (order of ship type is by typical design speed of ship type). It shows that the percentage of blasting repairing activity is higher for high-speed ships. In other words, design speeds or service speeds of different types of ships have some effects on hull blasting repairing activity.

In Table 2, one can easily find that for a particular relationship (Figs. 9-16), the values of $r^{2}$ for a linear and an exponential relationship are very close, even in some cases, values for exponential relationship are significantly lesser (Figs. 10 and 11).

Based on $r^{2}$ values, maximum relationships have a fair goodness of fit to linear relationship. Therefore, it is not biased to consider a general assumption that the hull blasting area is a function of ships' age, size (deadweight), and type and that they are linearly associated. More specifically, older and bigger ships are expected to have more blasting works than newer and smaller ships.

\subsection{Hull painting}

Initial investigations of pairs of variables of interests related to hull painting are shown in Figs. 17-24, and corresponding $r^{2}$ values assuming linear and nonlinear relationships (exponential) are presented in Table 3. Figures 17 and 18 indicate the relationship between hull painting area (observed values), average hull painting area by age group against ships' age (total painting repairing area for a particular age group divided by the total number of ships under the same age group), respectively. In Fig. 17, points are widely scattered, but in Fig. 18, points are less scattered, and this is 


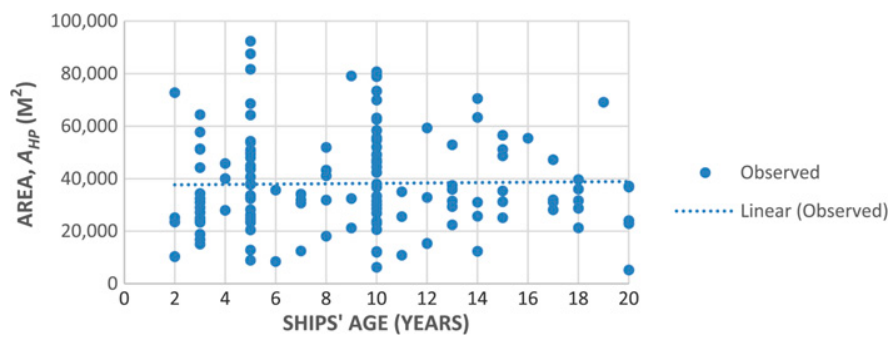

Fig. 17 Hull painting area versus age of sample ships

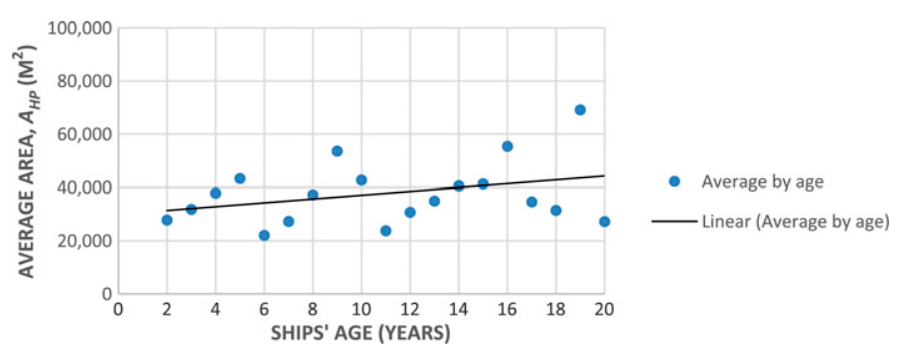

Fig. 18 Average hull painting area versus age of sample ships

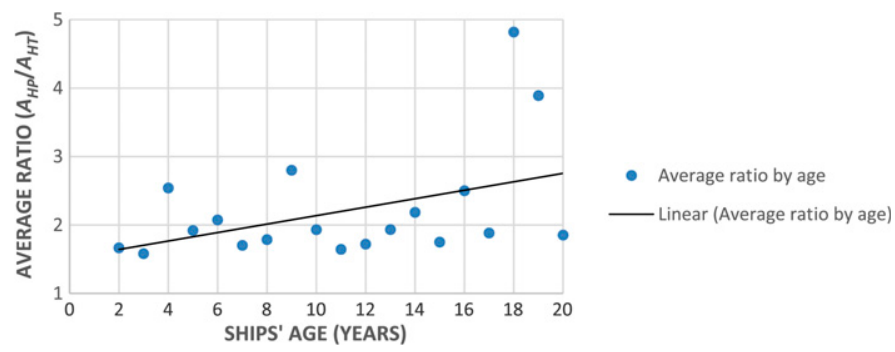

Fig. 19 Average ratio $\left(A_{H P} / A_{H T}\right)$ versus age of sample ships

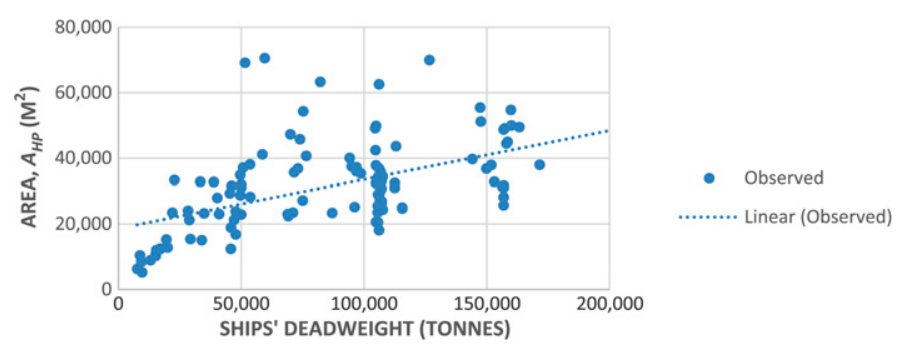

Fig. 20 Hull painting area versus deadweight of sample ships

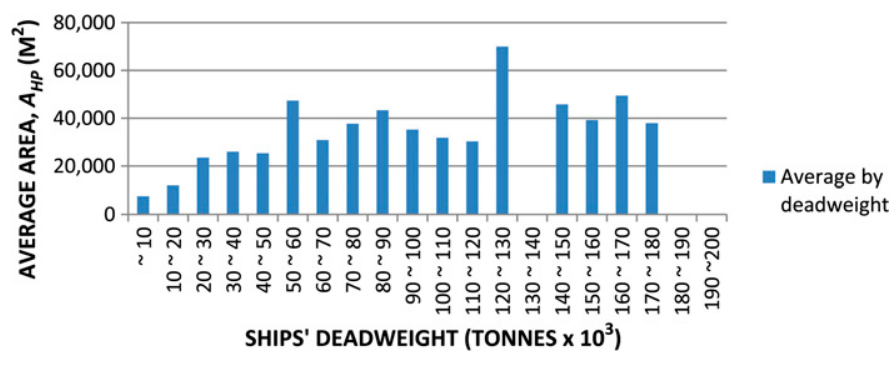

Fig. 21 Average hull painting area versus deadweight of sample ships

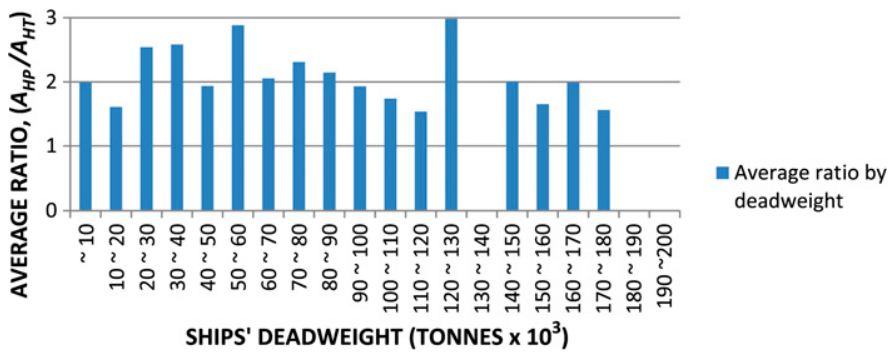

Fig. 22 Average ratio $\left(A_{H P} / A_{H T}\right)$ versus deadweight of sample ships

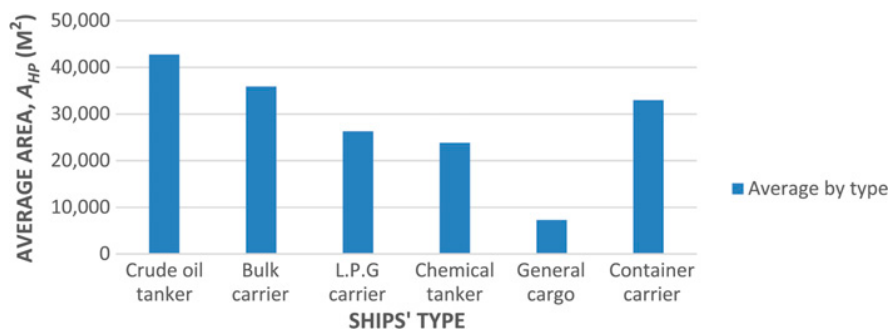

Fig. 23 Average hull painting area versus types by typical design speed order

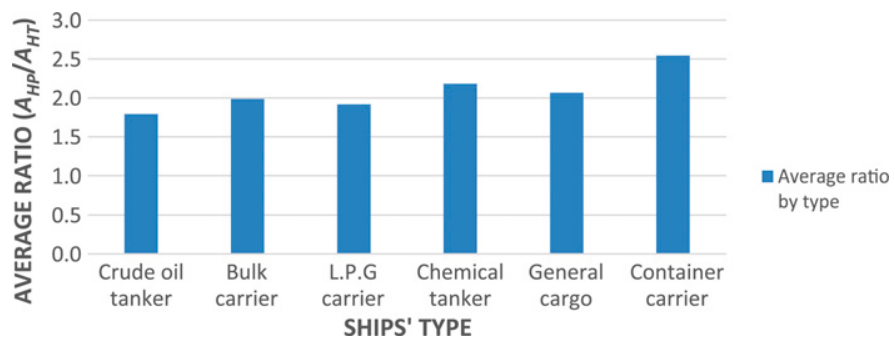

Fig. 24 Average ratio $\left(A_{H P} / A_{H T}\right)$ versus types by typical design speed order

Table 3 Summary of correlation coefficients under linear and exponential relationship

\begin{tabular}{ccc}
\hline & \multicolumn{2}{c}{$r^{2}$ value } \\
\cline { 2 - 3 } Figure No. & Linear relationship & Exponential relationship \\
\hline 17 & 0.0004 & 0.0010 \\
18 & 0.1177 & 0.1045 \\
19 & 0.2404 & 0.2648 \\
20 & 0.5945 & 0.5329 \\
21 & 0.4625 & 0.5117 \\
22 & $0.0832(-)$ & $0.0975(-)$ \\
23 & $0.3567(-)$ & $0.2702(-)$ \\
24 & 0.7537 & 0.7742 \\
\hline
\end{tabular}


supported by the higher $r^{2}$ value ( 0.0004 and 0.1177 , respectively) in Table 3 . In both cases, painting area $\left(A_{H P}\right)$ shows a trend of linear relationship with ships' age.

Figure 19 shows the relationship of the average ratio of hull painting area to hull total area $\left(A_{H P} / A_{H T}\right)$ against ships' age. It shows a trend of linear relationship with ships' age with $r^{2}$ value of 0.2404 (Table 3). Mathematically, it means that hull painting area has a positive and linear relationship with ships' age, which is in line with the assumption.

Figures 20 and 21 show the relationship between hull painting area (observed values), average hull painting area by the deadweight group against ships' deadweight (total painting repairing area for a particular deadweight group divided by the total number of ships under the same deadweight group), respectively. In Fig. 20, points are widely scattered, but in Fig. 21, points are less scattered. In both cases, painting area $\left(A_{H P}\right)$ shows a trend of strong linear relationship with ships' deadweight.

Figure 22 shows the relationship of the average ratio of hull painting area to hull total area $\left(A_{H P} / A_{H T}\right)$ against ships' deadweight. It shows a trend of linear relationship with ships' deadweight with $r^{2}$ value of 0.0832 with a negative slope (Table 3 ). It shows the same trend of Fig. 14. Mathematically, it means that the rate of change of deadweight is much higher than the rate of change in corresponding painting repairing area. It leads to lower ratio value for higher deadweight.

Figure 23 shows the relationship between average hull painting area by ship type against the types of ship with a linear relationship and $r^{2}$ value of $0.3567(-)$.

Figure 24 shows the relationship between the average ratio of hull painting area to hull total area by ship type $\left(A_{H B} / A_{H T}\right)$ against the types of ships with a linear relationship and $r^{2}$ value of $0.2702(-)$.

Table 3 illustrates the values of $r^{2}$ for a linear and an exponential relationship. One can easily find that for a particular relationship (refer to Figs. 17-24), the values of $r^{2}$ for a linear and an exponential relationship are very close, even in some cases, values for exponential relationship are significantly lesser (Figs. 20 and 23).

Based on $r^{2}$ values, maximum links have a fair goodness of fit to linear relationship. Therefore, it is justified to make a general assumption that the hull painting area is a function of ships' age, size (deadweight), and type and is linearly associated. More specifically, older and bigger ships are expected to have more painting works than newer and smaller ships.

\section{Preliminary estimation of blasting and painting areas}

\subsection{Introduction}

There is no doubt that the quantity of blasting and painting repairing works is significantly influenced by the physical size of a ship irrespective of their design parameters. Physically bigger ships will require more blasting and painting repairing works compared to smaller ships. The size of a ship can be defined in various ways using different parameters, such as displacement, deadweight, gross tonnage, and principal dimensions. In this article, the physical size of a ship refers to the physical dimensions of a ship, such as length, breadth, and depth. In this section, blasting and painting repairing works are considered to be a func- tion of ships' principal dimensions and hull total area, respectively. Accordingly, blasting and painting repairing areas of hull and other hull locations are analyzed as a function of ships' principal dimensions and total area, respectively. In other words, blasting and painting repairing areas of hull and its individual hull location areas are considered as dependent variables, and corresponding ships' principal dimensions with appropriate combinations (Table 4) and individual hull location actual area are considered as independent variables. Various functional relationships are drawn using these various sets of dependent variables and independent variables.

The functional relationship of different hull locations is different with different combinations of principal dimensions of a ship. Functional equations shown below are the examples of a mathematical relationship between hull blasting and hull painting areas (the dependent variables) and corresponding ship's dimensions and hull location actual area (the independent variables), respectively.

$$
\begin{aligned}
& A_{H B}=f\left\{L_{O A} \times\left(B_{\text {mld }}+2 \times D_{\text {mld }}\right)\right\} \\
& A_{H B}=f\left(A_{H T}\right) \\
& A_{H P}=f\left\{L_{O A} \times\left(B_{\text {mld }}+2 \times D_{\text {mld }}\right)\right\} \\
& A_{H P}=f\left(A_{H T}\right)
\end{aligned}
$$

\subsection{Methodology}

Based on the boundary condition applied to the functional relationship between blasting and painting repairing works and ships' dimensions and individual hull locations area, the equation must satisfy the condition that for a zero hull area or a zero hull location area, blasting and painting areas are zero. Mathematically, the line of the equation must pass through the origin $(0,0)$. Therefore, the required equation is considered to be $Y=m \times X$ form, where $Y$ is the quantity of blasting or painting repairing areas $\left(\mathrm{m}^{2}\right), X$ the corresponding ship's dimensions in appropriate combinations or actual individual area $\left(\mathrm{m}^{2}\right)$, and $m$ a constant slope.

Initial investigation on pairs of variables of interests related to hull blasting and painting areas is presented in Figs. 25-48. Figures 25-36 depict the behavior of hull blasting repairing works on ship's dimensions and individual hull location area, respectively. All these figures reveal that with the increase of ships' dimensions, the blasting quantity is also increased linearly. Figures $37-48$ depict the behavior of hull painting repairing works on ship's dimensions and individual location area, respectively. All these figures reveal that with the increase of ships' dimensions, the painting quantity is also increased linearly. All these figures support the assumption made earlier that the size (length, breadth, and depth) of a ship has a positive impact on hull blasting and painting repairing works, and they are linearly associated.

Surprisingly, painting repairing works have a stronger dependency on the ship's dimensions than that of blasting, which is very much expected. The probable reason is that the quantity of painting repairing work is truly governed by the area of hull irrespective of blasting repairing works. One may recall that blasted area is covered with one or two touch-up coats followed 
Table 4 Summary of slope and $r^{2}$ values for various relationships

\begin{tabular}{|c|c|c|c|c|c|}
\hline Location & $Y$ & $X$ & $m$ & \multicolumn{2}{|c|}{$r^{2}$ values } \\
\hline TS (topside) & $A_{T S B}$ & $\left\{L_{O A} \times 2\left(D_{m l d}-T_{\max }\right)\right\}$ & 0.1212 & 0.0200 & NA \\
\hline BT (boottop) & $A_{B T B}$ & $\left\{L_{O A} \times 2\left(T_{\max }-T_{\min }\right)\right\}$ & 0.1570 & 0.0039 & NA \\
\hline BT (boottop) & $A_{B T B}$ & $A_{B T}$ & 0.1570 & 0.0036 & NA \\
\hline VB (vertical bottom) & $A_{V B B}$ & $\left(L_{O A} \times 2 T_{\min }\right)$ & 0.2185 & 0.1538 & NA \\
\hline FB (flat bottom) & $A_{F B B}$ & $A_{F B}$ & 0.0954 & 0.0080 & NA \\
\hline VS (vertical side) & $A_{V S B}$ & $\left(L_{O A} \times 2 T_{\max }\right)$ & 0.1804 & 0.0329 & NA \\
\hline VS (vertical side) & $A_{V S B}$ & $A_{V S}$ & 0.1584 & 0.0200 & NA \\
\hline HULL (total) & $A_{H B}$ & $\left\{L_{O A} \times\left(B_{m l d}+2 D_{m l d}\right)\right\}$ & 0.1153 & 0.0128 & 0.0447 \\
\hline HULL (total) & $A_{H B}$ & $A_{H T}$ & 0.1274 & 0.0050 & 0.0363 \\
\hline TS (topside) & $A_{T S P}$ & $\left\{L_{O A} \times 2\left(D_{\operatorname{mld}}-T_{\max }\right)\right\}$ & 1.5720 & 0.3975 & 0.5532 \\
\hline VB (vertical bottom) & $A_{V B P}$ & $A_{V B}$ & 2.9106 & 0.4219 & 0.4682 \\
\hline FB (flat bottom) & $A_{F B P}$ & $\left(L_{O A} \times B_{m l d}\right)$ & 0.9925 & 0.3294 & 0.4380 \\
\hline FB (flat bottom) & $A_{F B P}$ & $A_{F B}$ & 1.5170 & 0.3605 & 0.4666 \\
\hline VS (vertical side) & $A_{V S P}$ & $\left(L_{\mathrm{OA}} \times 2 T_{\max }\right)$ & 2.5569 & 0.6369 & 0.6216 \\
\hline VS (vertical side) & $A_{V S P}$ & $A_{V S}$ & 2.2781 & 0.5852 & 0.5934 \\
\hline HULL (total) & $A_{H P}$ & $\left\{L_{O A} \times\left(B_{m l d}+2 D_{m l d}\right)\right\}$ & 1.6353 & 0.6382 & 0.6333 \\
\hline HULL (total) & $A_{H P}$ & $A_{H T}$ & 1.8152 & 0.6454 & 0.6375 \\
\hline
\end{tabular}

NA, Not Applicable.

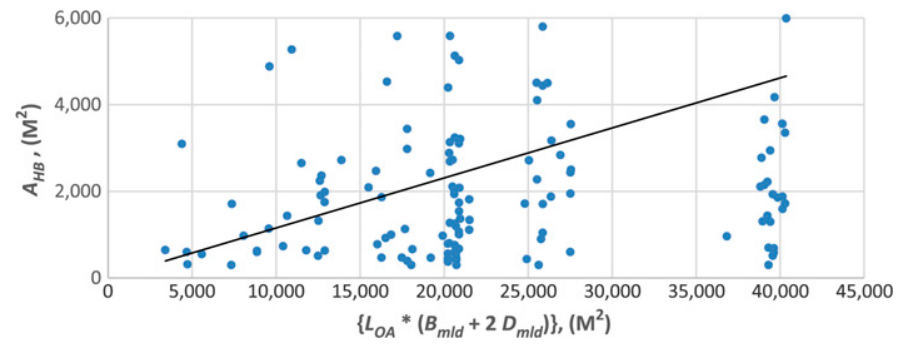

Fig. 25 Hull blasting area as a function of ship's dimensions

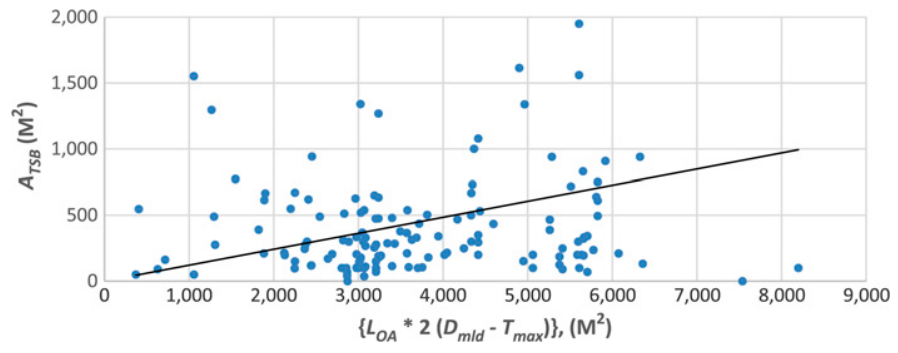

Fig. 27 Topside blasting area as a function of ship's dimensions

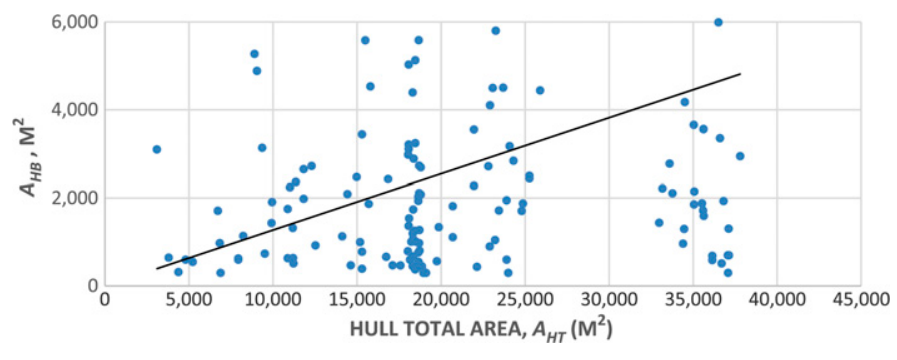

Fig. 26 Hull blasting area as a function of hull total area

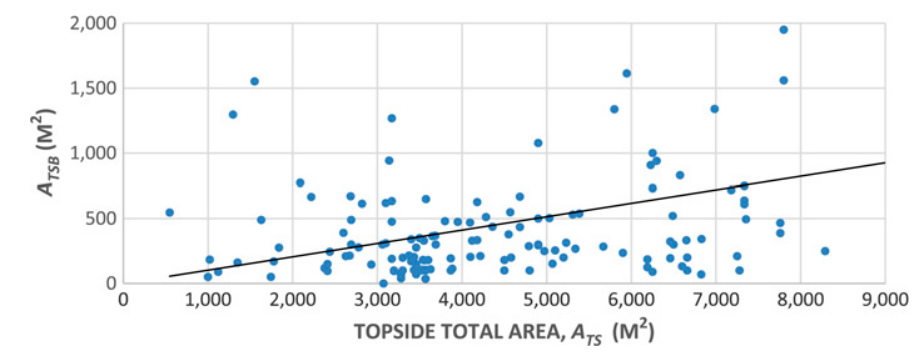

Fig. 28 Topside blasting area as a function of topside total area 


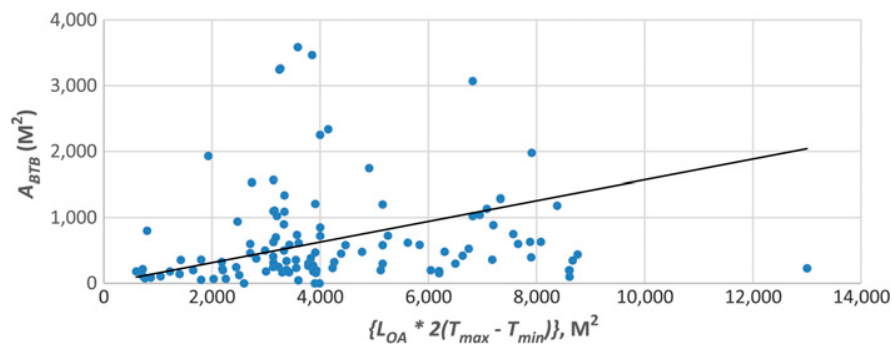

Fig. 29 Boottop blasting area as a function of ship's dimensions

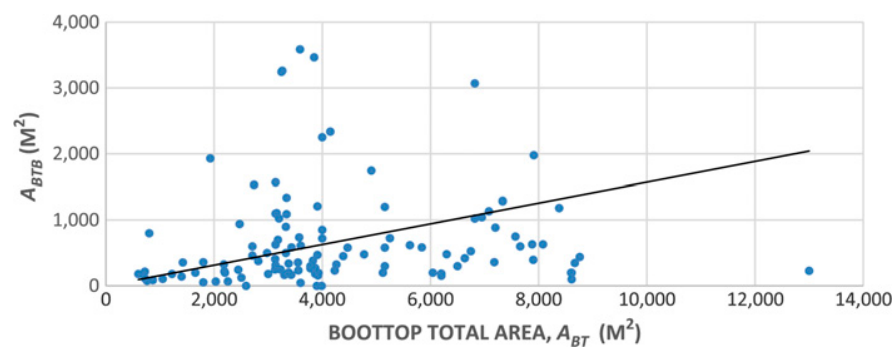

Fig. 30 Boottop blasting area as a function of boottop total area

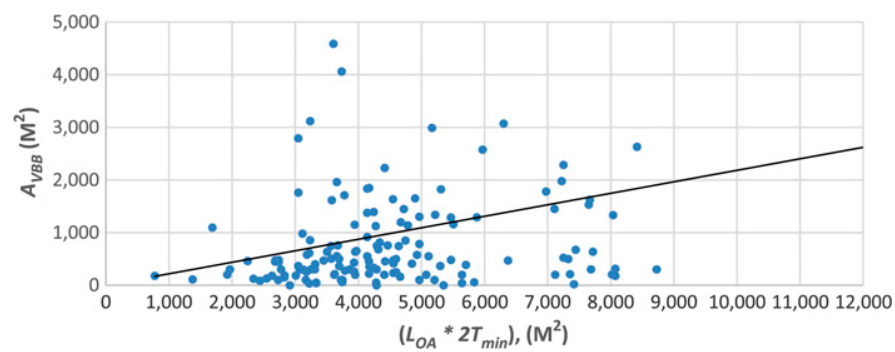

Fig. 31 Vertical bottom blasting area as a function of ship's dimensions

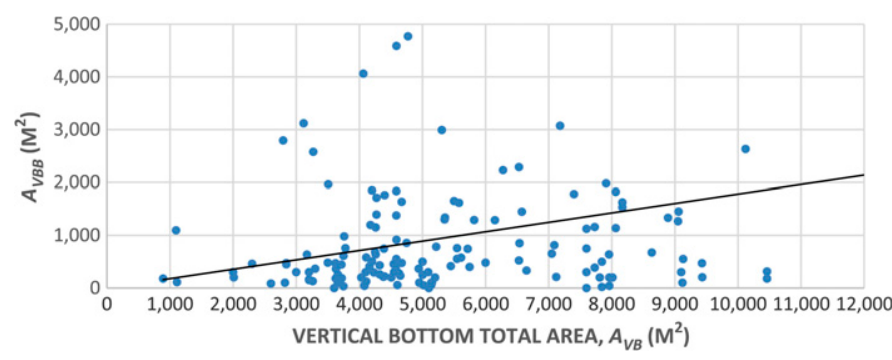

Fig. 32 Vertical bottom blasting area as a function of vertical bottom total area

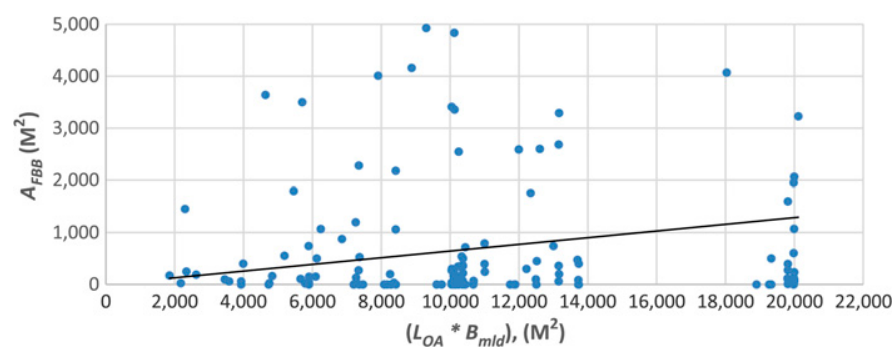

Fig. 33 Flat bottom blasting area as a function of ship's dimensions

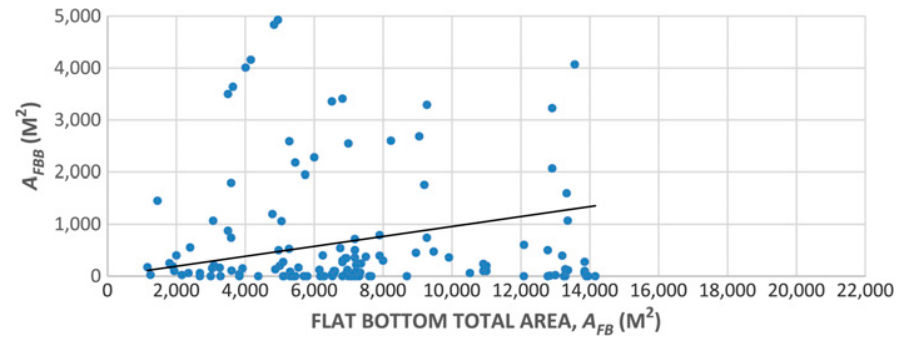

Fig. 34 Flat bottom blasting area as a function of flat bottom total area

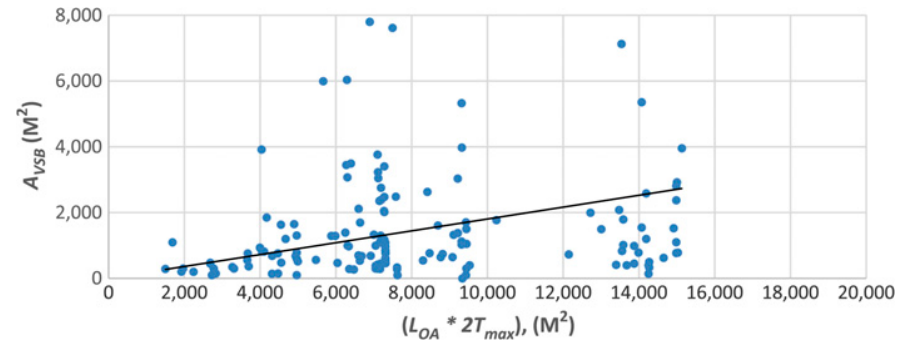

Fig. 35 Vertical side blasting area as a function of ship's dimensions

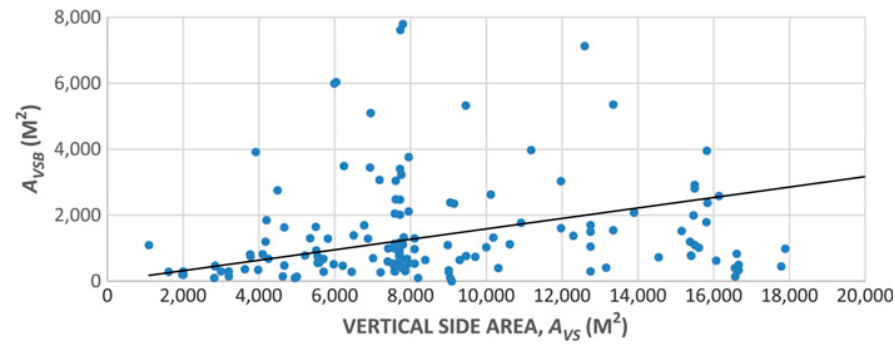

Fig. 36 Vertical side blasting area as a function of vertical side total area

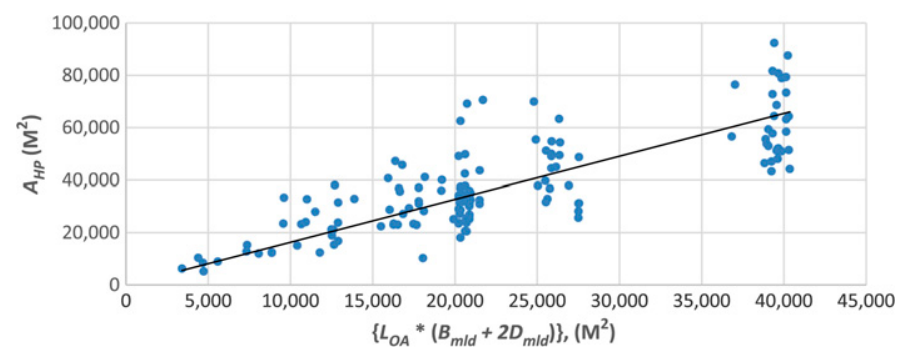

Fig. 37 Hull painting area as a function of ship's dimensions

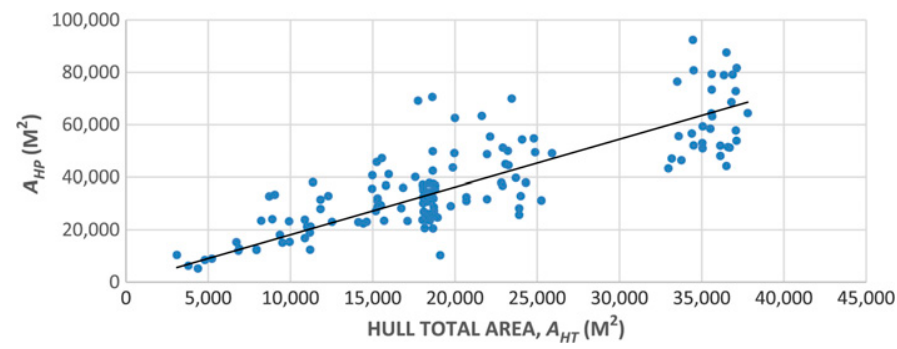

Fig. 38 Hull painting area as function of hull total area 


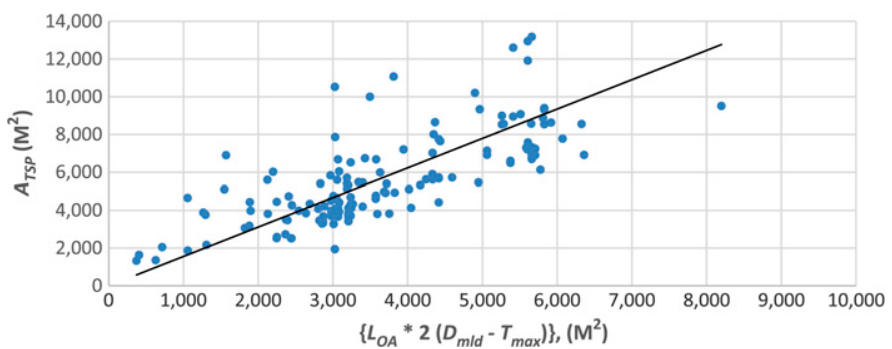

Fig. 39 Topside painting area as a function of ship's dimensions

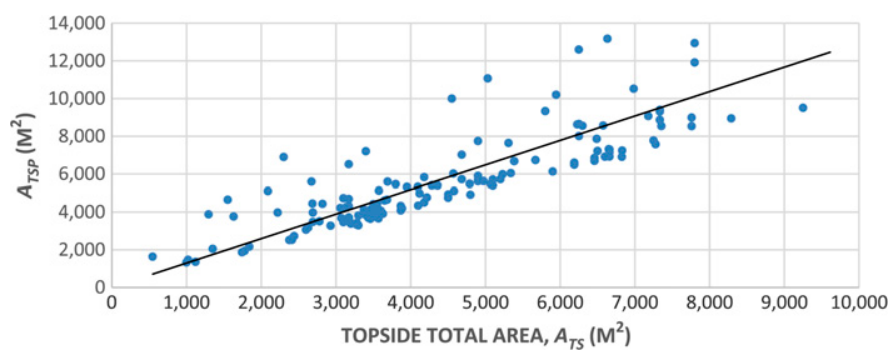

Fig. 40 Topside painting area as a function of topside total area

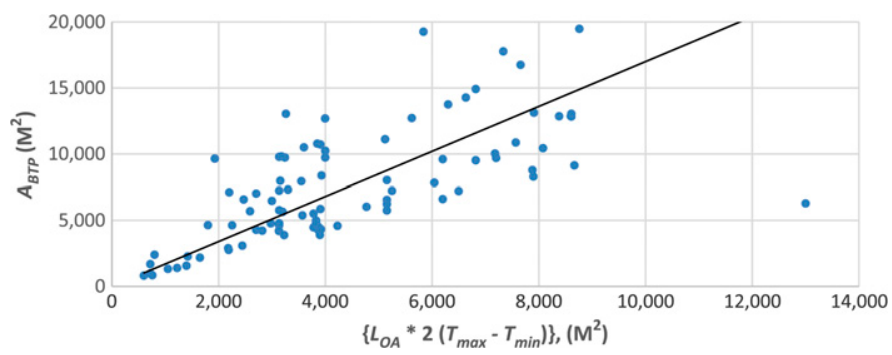

Fig. 41 Boottop painting area as a function ships dimensions

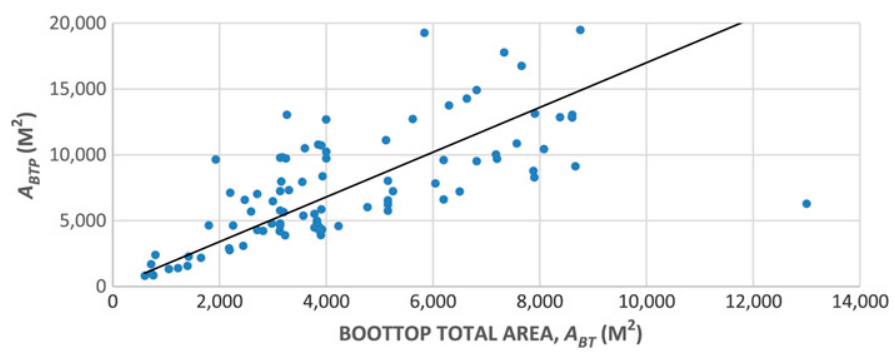

Fig. 42 Boottop painting area as a function of boottop total area

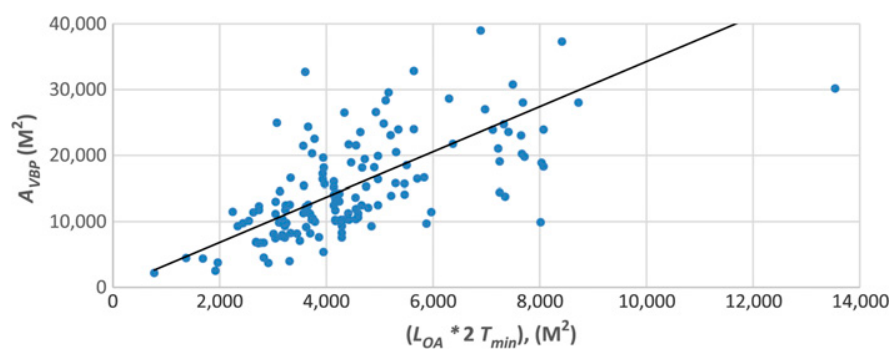

Fig. 43 Vertical bottom painting area as a function of ship's dimensions

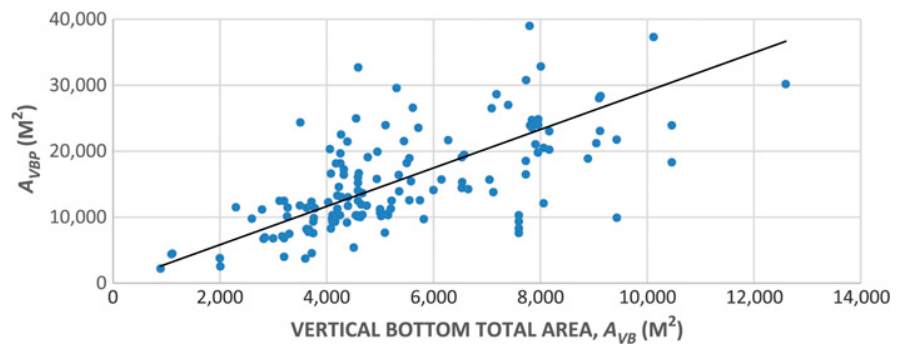

Fig. 44 Vertical bottom painting area as a function of vertical bottom total area

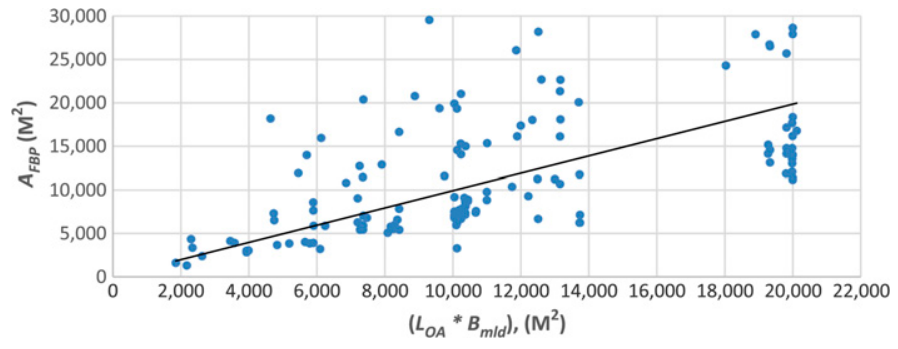

Fig. 45 Flat bottom painting area as a function of ship's dimension

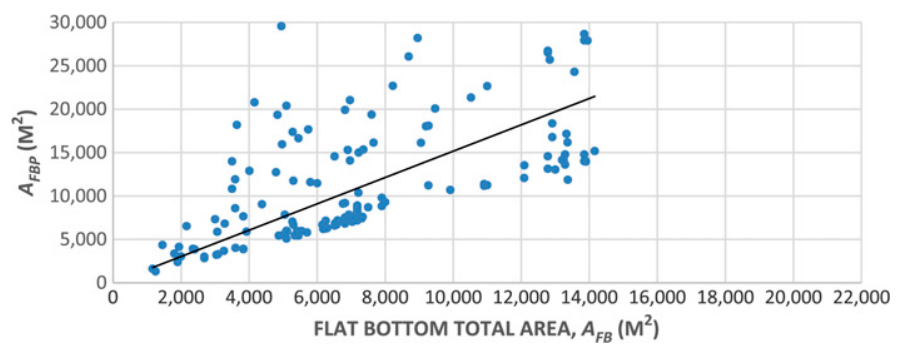

Fig. 46 Flat bottom painting area as a function of flat bottom total area

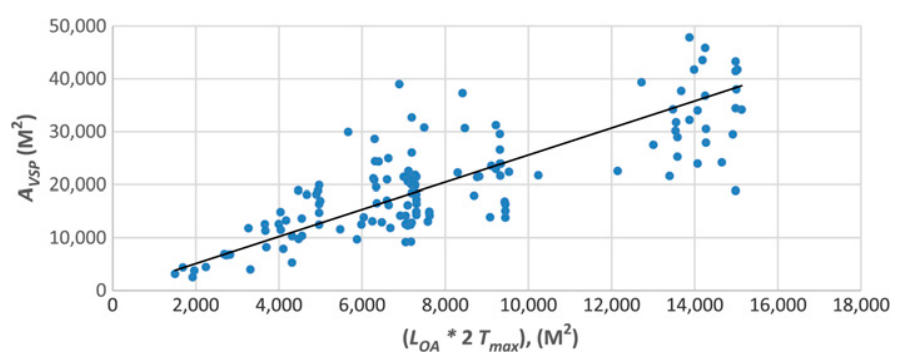

Fig. 47 Vertical side painting area as a function of ship's dimensions

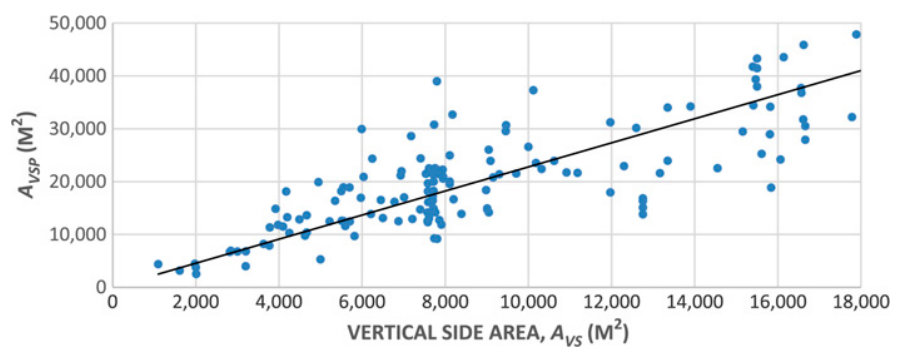

Fig. 48 Vertical side painting area as a function of vertical side total area 
by one or two full coats to the entire area. Thus, total painting area depends on hull total area. Total blasting area also depends on hull total area but with a lower magnitude, which is reflected in the form lower constant slope value $(m)$ than that of painting repairing works. As such, the bigger ships (dimensionally) will require greater blasting and painting repairing works.

Using an equation of the form $Y=m \times X$ and the data for all figures, the average value of " $m$ " is calculated for each function and is presented in Table 4 . The estimated value of " $m$ " may be helpful for preliminary assessment of the quantity of blasting and painting repairing works for individual location area before docking.

\section{Discussion}

This article reveals some very fundamental information regarding the hull total area, blasting area, painting area and the coating repairing works of various types of ships. It breakdowns the average hull total area, blasting area, and painting area against the hull locations, that is, topside, boottop, vertical bottom, and flat bottom. The contribution of individual locations in hull total area, hull blasting area, and hull painting area is presented in a tabular form in Table 5 and in a graphical form in Fig. 49.

The average hull total area consists of $22 \%, 17 \%, 26 \%$, and $35 \%$ for topside, boottop, vertical bottom, and flat bottom, respectively, irrespective of age, deadweight, and type. The average hull blasting work is about $14 \%$ of hull total area $\left(A_{H T}\right)$, comprising $2 \%, 3 \%, 5 \%$, and $4 \%$ for topside, boottop, vertical bottom, and flat bottom, respectively, irrespective of age, deadweight, and type. The average hull painting work is $185 \%$ of hull total area $\left(A_{H T}\right)$ comprising of $28 \%, 24 \%, 77 \%$, and $56 \%$ for topside, boottop, vertical bottom, and flat bottom, respectively, irrespective of age, deadweight, and type. It is important to note that average blasting

Table 5 Average area of location, blasting and painting against locations of sample ships

\begin{tabular}{lccr}
\hline & \multicolumn{3}{c}{ Average area (\%) } \\
\cline { 2 - 4 } \multicolumn{1}{c}{ Locations $\downarrow$} & Hull & Blasting & Painting \\
\hline Topside & 22 & 2 & 28 \\
Boottop & 17 & 3 & 24 \\
Vertical bottom & 26 & 5 & 77 \\
Flat bottom & 35 & 4 & 56 \\
Total & 100 & 14 & 185 \\
\hline
\end{tabular}

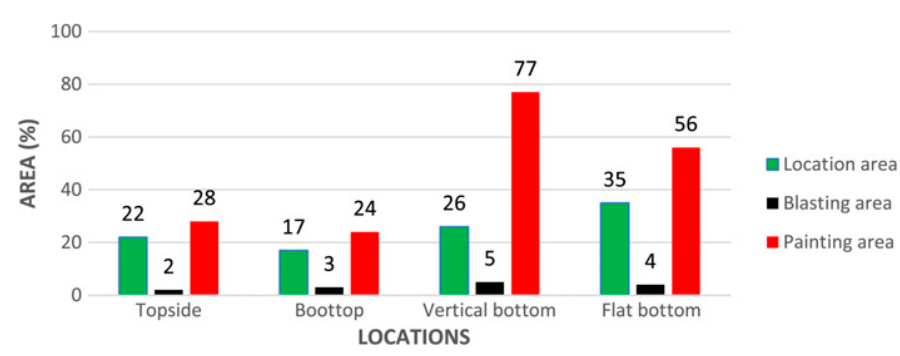

Fig. 49 Average hull location, blasting and painting area versus hull locations of sample ships areas (\%) against locations are always less than average painting areas (\%) against locations. The reason is that blasting is always spot, which means that blasting area is less than hull total area, and painting is always multiple coats, which means that painting area is more than hull total area.

At this point, it is important to note that whatever be the blasting area, there will be single or multiple touch-up coats to blasted area followed by single or multiple full coats of entire hull area. It explains why total painting area (adding all painted area, touch-up and full coats) is always much greater than blasting area. It also explains why total painting area is always higher than hull total area (Figs. 26 and 38; Table 5).

In reality, there are cases where the blasted area is very nominal compared to hull total area, but total painted area is more than two times of hull total area.

The study also found blasting and painting parameters for different types of ships and presented the result in both tabular and graphical form in Table 6 and Fig. 50, respectively. Container carriers claim the highest blasting areas (\%) followed by bulk carriers, chemical tankers, and so on, whereas container carriers claim the largest painting areas (\%) followed by chemical tankers, bulk carriers, and so on. These basic findings can be used as a sort of proven guide for preliminary estimation purpose.

The influence of independent variables that handle hull-coating repairing works (blasting and painting), such as ships' age, deadweight, and type, is demonstrated in Figs. 9-24. Figures 9-16 describe the relationship of blasting area on ships' age, deadweight, and type. Detail explanations of blasting-related figures are given in section 5.1. All these figures support the initial assumptions that the aforementioned independent variables have a positive influence on the hull blasting repairing works. However, the responses widely varied from variable to variable, which is very much expected. Quick responses are observed for ships' age and type and comparatively slower for size. Figures 9-11

Table 6 Average blasting and painting areas against types of sample ships

\begin{tabular}{lcc}
\hline & \multicolumn{2}{c}{ Average area (\%) } \\
\cline { 2 - 3 } \multicolumn{1}{c}{ Types } & Blasting & Painting \\
\hline Crude oil tanker & 12 & 178 \\
LPG carrier & 16 & 197 \\
Chemical tanker & 16 & 216 \\
Bulk carrier & 22 & 198 \\
Container carrier & 38 & 269 \\
\hline
\end{tabular}

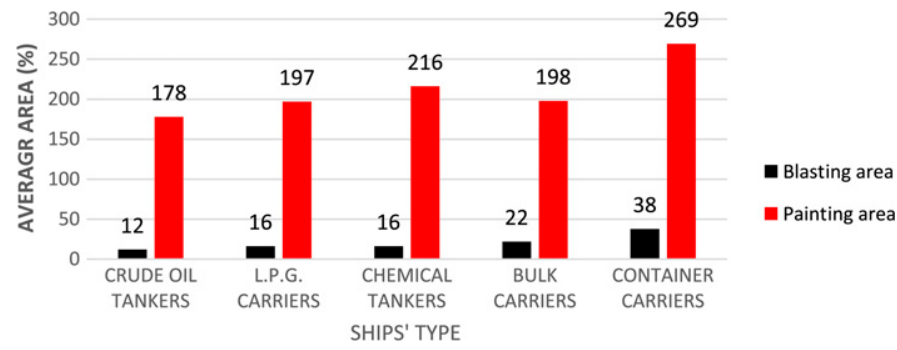

Fig. 50 Average hull blasting and painting area versus types of sample ships 
show that age of a ship has very significant and positive contribution to hull blasting area, and they are linearly associated. It means that older ships would require more blasting area compared to newer ships. Figures 12-14 show that the influence of the size of a ship (deadweight) on hull blasting area is not as strong as ship's age. It means that bigger ships do not necessarily require more hull blasting activities compared to smaller ships. Mathematically, the negative slope of the linear regression line in Fig. 14 confirms that the impact of deadweight on hull blasting repair is not substantial (Fig. 13). Figures 15 and 16 show that type of a ship (container carriers, bulk carriers, liquefied natural gas (LNG) carriers, crude oil tankers, etc.) has a significant impact on hull blasting area. It illustrates that different types of a ship will have a different scope of hull blasting activities even though those are of same age and deadweight.

Figures 17-24 demonstrate the relationship of painting to ships' age, deadweight, and type. Detail explanations of blastingrelated figures are given in section 5.2. Figures 17-19 show that the age of a ship has very significant and positive contribution to the hull painting area; they are linearly associated. It means that older ships would require more painting activities (more painting area) compared to newer ships. Figures 20-22 show that the deadweight of a ship has a significant impact on the hull painting area. It means that bigger ships will have more hull painting activities (more painting area) compared to smaller ships, which is naturally true. Figures 23 and 24 show the influence of the type of a ship (container carriers, bulk carriers, LNG carriers, crude oil tankers, etc.) on the hull painting works. It means that different types of ships will have a different scope of hull painting activities even though those are of same age and deadweight.

Detail descriptions and explanations about the trend of blasting area (Figs. 9-16) and painting area (Figs. 17-24) on age, deadweight, and type of ships are provided in section 5.1 and 5.2, respectively. Referring to Tables 2 and 3 , it will be unbiased to draw the conclusion that the blasting and painting areas are linearly related to ships' age, deadweight, and type.

Figures $25-36$ and $37-48$ demonstrate the relationship of blasting repairing area and painting repairing area on corresponding ships' dimensions and actual area, respectively. Detail explanations of figures are given in section 6. Figures 25 and 26 show that the ships' dimensions for hull total area and actual hull total area have a strong relationship with hull blasting repairing works, respectively. Same phenomena, but with different magnitudes, is observed in the case of topside, boottop, vertical bottom, flat bottom, and vertical side in Figs. 27 and 28, 29 and 30, 31 and 32, 33 and 34, and 35 to 36, respectively. Figures 37 and 38 show that the hull painting repairing works have a strong positive relationship with ships' dimensions and actual hull area, respectively. Figures 39 and 40, 41 and 42, 43 and 44, 45 and 46, and 47 and 48 also demonstrate the strong relationship with topside, boottop, vertical bottom, flat bottom, and vertical side, respectively. The trend of the relationship suggests that hull blasting and painting repairing works have a strong positive and linear relationship to a ship's dimensions.

The comparison of $r^{2}$ values of various relationships under linear and exponential relationships is highlighted only for a better understanding of the trend of dependent variables on the independent variable. No attempt is made to develop and propose any mathematical model to estimate blasting and painting repairing areas regarding age, deadweight, and type of a ship.
Table 4 strongly suggests that blasting and painting repairing works have significant dependency on the ship's dimensions. One may use the table to estimate the expected hull blasting and painting repairing scope, using ships' dimensions and appropriate " $m$ " value from the table, before docking. This estimated scope of coating repairing works can also be used to prepare the schedule and budget for the works.

However, with all of the above findings and limitations of the study concerning sample size, it is logical and unbiased to conclude that all these independent variables have a collective and significant impact on the hull coating repairing works, and that they are apparently linearly associated.

\section{Conclusions}

This article attempts to demonstrate the trends of hull coating renewal in ship repairing concerning age, deadweight, and type of ships. This analysis suggests that hull coating repairing works are a function of ships' age, deadweight, and type but at different degrees of responses. It also reveals some fundamental basis for the estimation of average hull blasting and painting areas for various ships' age, deadweight, and type. All independent variables are mostly linearly associated with the dependent variable. Hence, it can be concluded that ships' age, deadweight, and type have a significant impact on the hull coating repairing works, and they are mostly linearly associated. No attempt was made to formulate and develop a mathematical model that adequately fits the behavior of the dependent variables, hull coating quantity, concerning independent variables, ships' age, deadweight, and type. It could be a future scope of research work.

Table 4 may be useful for ship operators for estimating hull coating repairing scopes before a ship's docking and for preparing the necessary budget.

It is interesting to note that for a ship irrespective of type, its hull blasting area $\left(A_{H B}\right)$ is strongly related to its age (Fig. 10), and its hull painting area $\left(A_{H P}\right)$ is strongly related to deadweight (Fig. 20). However, the physical dimensions and actual hull area of a ship have a strong influence on both, blasting and painting areas. Therefore, one may choose to estimate blasting area based on age, painting area based on deadweight or both, blasting and painting areas, based on physical dimensions.

However, despite the limitations of sample size, the various findings of this research can be useful to ship operators and shipyards. Using these as guidelines, ship operators and shipyards may be able to estimate expected hull coating works of a ship to be handled and also a proper dry-docking schedule and budget.

This article should be considered as a first step to knowing the relationship that exists between the possible variables in hull coating renewal in ship repairing. These works can be fine-tuned with a larger sample size. A multiple linear regression model may then be considered to develop a mathematical model (Dev \& Saha $2015,2016)$ that will be able to predict the expected hull coating repairing works concerning ships' age, deadweight, type, and other potential variables, if any.

\section{References}

Broderick, D., Wright, P., and Kattan, R. 2012 Exploring the link between structural complexity and coating performance, Proceedings, 
$11^{\text {th }}$ International Marine Design Conference (IMDC), June 11-14, Glasgow, UK.

Dev, A. K. ANd SaHA, M. 2015 Modeling and analysis of ship repairing time, Journal of Ship Production and Design, 31, 2, 129-136.

Dev, A. K. AND SAHA, M. 2016 Modeling and analysis of ship repairing labor, Journal of Ship Production and Design, 32, 2, 1-14.

Garbatov, Y., Soares, C. G., and Wang, G. 2006 Nonlinear time dependent corrosion wastage of deck plate of ballast and cargo tanks of tankers, American Society of Mechanical Engineers, 129, 1, $48-55$.

Hiromi, S., Matsushita, H., Song, Y., NaKai, T., and YuYa, N. 2006 Thickness reduction due to flow accelerated corrosion of shipboard piping, ClassNK Technical Bulletin, 35-56.
Jotun Coating Manual. 2001 Surface preparation and cleaning, Chapter 12, 12.42.

Nakai, T., Matsushita, H., and Yamamoto, N. 2007 Assessment of corroded conditions of Webs of Hold Frames with Pitting Corrosion, ClassNK Technical Bulletin, 23-32.

O'Donnell, W. J. 2006 Corrosion fatigue: recent developments and future needs, Journal of Marine Design and Operations, 10, 27-37.

Paik, J. K., Thayamballi, A. K., Kim, S. K., and Yang, S. H. 1998 Ship hull ultimate strength reliability considering corrosion, Journal of Ship Research, 42, 2, 154-165.

YAmamoto, N. AND IKeGami, K. 1998 A study on the degradation of coating and corrosion of ship's hull based on the probabilistic approach, Journal of Offshore Mechanics and Arctic Engineering, 120, 121-128. 